\title{
PENGEMBANGAN OBJEK 3D MEMANFAATKAN PIRAMIDA HOLOGRAM BERBASIS SMARTPHONE MATERI SISTEM GERAK MANUSIA
}

\author{
Zaki Daffa Ferdiansyah, Dedi Kuswandi, Yerry Soepriyanto \\ Teknologi Pendidikan, Fakultas Ilmu Pendidikan, Universitas Negeri Malang. \\ Jl. Semarang No.5, Malang, 65145, Indonesia. \\ Zakidaffaf@gmail.com
}

\section{Article History}

Received: 15 Maret 2021, Accepted: 11 April 2021, Published: 20 Februari 2022

\begin{abstract}
Abstrak
Penelitian dan pengembangan bertujuan menghasilkan produk berupa objek 3D memanfaatkan piramida hologram berbasis smartphone materi sistem gerak manusia. Research and Development (R\&D) merupakan penelitian dan pengembangan yang mengacu pada model Lee \& Owen dengan tahapan (analysis, design, development, implementation). Dengan penerapan media objek 3D sebagai pelengkap dalam pembelajaran IPA, media sebagai pelengkap berarti media diterapkan untuk melengkapi materi yang diterima siswa di dalam kelas. Hasil dari uji kelayakan produk yang telah diujikan kepada ahli media, ahli materi dan siswa mendapatkan respon positif dan layak. Sehingga dapat disimpulkan media objek 3D memanfaatkan piramida hologram berbasis smartphone materi sistem gerak manusia layak digunakan sebagai media pembelajaran di dalam kelas, dengan adanya media objek 3D memanfaatkan piramida hologram berbasis smartphone dapat memberikan kemudahan dalam pembelajaran, memotivasi siswa untuk belajar, menampilkan media yang menarik untuk siswa.
\end{abstract}

Kata kunci: Media Pembelajaran; Objek 3D Digital; Smartphone, Piramida Hologram

\begin{abstract}
Research and development with the aim of producing a product in the form of a $3 D$ object utilizing a smartphone-based hologram piramida of human movement system material. Research and Development $(R \& D)$ is research and development that refers to the Lee \& Owen model with stages (analysis, design, development, implementation). With the application of $3 D$ object media as a complement in science learning, media as a complement means that the media is applied to complement the material received by students in the classroom. The results of the product feasibility test that have been tested on media experts, material experts and students get a positive and feasible response. So it can be concluded that the 3D object media utilizes a smartphone-based hologram piramida, the human motion system material is suitable for use as a learning medium in the classroom, with the presence of $3 D$ object media utilizing smartphone-based hologram piramidas can provide convenience in learning, motivate students to learn, display attractive media for students.
\end{abstract}

Keyword: Learning Media; 3D Digital Object; Smartphone; Hologram Pyramid 


\section{PENDAHULUAN}

Perkembangan teknologi komunikasi dan informasi yang sangat cepat ini tentunya memberikan manfaat yang sangat besar dalam kehidupan manusia. Berbagai bidang kehidupan selalu memanfaatkan teknologi untuk membantu mengatasi setiap masalah-masalah yang dihadapinya, teknologi juga sangatlah berpengaruh bagi aspek manusia kususnya di bidang Pendidikan. Karena pendidikan adalah pondasi utama atau awal dalam pembangunan nasional. Salah satu bagian pendidikan adalah pembelajaran saat ini guru dituntut mampu membuat kegiatan belajar yang benar-benar dapat membuat siswa memiliki pengetahuan baik secara teori dan praktek. Dalam hal ini, pendidik harus pintar-pintar menemukan ataupun menciptakan suasana belajar yang menyenangkan dan juga memudahkan siswa untuk memahami, menafsirkan, dan mengaitkan materi pelajaran yang dipelajarinya (Kadir, 2013).

Pada proses pembelajaran siswa diharapkan mampu memanfaatkan penggunaan indra sebaik mungkin, baik itu penggunaan indra penglihatan, indra pendengaran ataupun kontak fisik secara langsung, penggunaan teknologi di dalam kelas membantu memfasilitasi guru menstransfer materi kepada siswa dengan baik, serta teknologi bisa menciptakan suasana yang tidak membosankan di dalam kelas (Resnick, 2002)“ fungsi penggunaan teknologi dalam modernisasi Pendidikan terdapat 3 hal penting yang harus dikaji ulang terkait perkembangan dunia Pendidikan: bagaimana siswa belajar, apa yang siswa pelajari, kapan dan dimana siswa belajar".

Fungsi media yaitu sebagai alat penyampai informasi kepada siswa. Kata Media adalah bahasa Latin, yang terbentuk dari kata jamak medium yang artinya "perantara" yaitu sebagai perantara sumber pesan dengan menerima pesan (Hermawan dkk., 2007).Penggunaan media pembelajaran secara umum mempunyai manfaat yaitu: menggambarkan sesuatu agar tidak terlalu verbal, mengatasi keterbatasan waktu, ruang, dan daya indra, meningkatkan motivasi perserta didik untuk giat belajar, memberikan pengalaman yang baru kepada siswa, memungkinkan siswa belajar secara mandiri sesuai kemampuan siswa tersebut. Media adalah alat penyampai segala informasi mengenai suatu materi yang dibagikan oleh pendidik kepada peserta didik (Andriyani dkk., 2020)

Dalam pembelajaran terdapat mata pelajaran llmu Pengetahuan Alam yang sangat penting diajarkan karena sangatlah berguna untuk kehidupan manusia (Kurniawan dkk., 2019) dalam penelitiannya berpendapat bahwa ilmu pengetahuan alam (IPA) merupakan kejadian yang bersifat kebendaan yang pada dasarnya terdiri dari hasil observasi, induksi dan uji coba. IPA atau sains merupakan usaha yang dipahami manusia tentang alam semesta melalui pengamatan yang tepat pada sasaran, serta prosedur yang dijelaskan dengan penalaran sehingga mendapatkan hasil kesimpulan (Saraswati, 2017)

Pembelajaran IPA di SMP dikembangkan sebagai mata pelajaran ilmu integratif bukan sebagai pendidikan disiplin ilmu. Keduanya sebagai pendidikan yang berorientasi aplikatif, kemampuan berfikir, rasa ingin tahu, kemampuan dalam belajar, dan membangun sikap peduli dan bertaggung jawab pada lingkungan dan sosial. Pada mata pelajaran Ilmu Pengetahuan Alam di SMP terdapat materi Sistem Gerak Manusia. Tujuan mempelajari materi sistem gerak manusia adalah mengidentifikasi struktur anatomi tulang manusia dengan benar. Mengidentifikasi struktur anatomi tulang manusia adalah hal yang sangatlah penting dalam mempelajari sistem gerak manusia, pada materi tersebut siswa mengamati struktur bagian dalam tulang. Kendala yang sering ditemukan pada saat pengamatan, guru hanya menjelaskan dengan verbal, serta membagikan buku yang minim memberikan gambaran objek sehingga murid kurang memahami dengan apa yang dijelaskan oleh guru di dalam kelas dan objek strukutur anatomi tulang manusia yang dipelajari bentuknya besar, sehingga tidak bisa dipelajari dimana saja. 
Dengan permasalahan tersebut dibutuhkan media 3 dimensi Sistem Gerak Manusia yang manampilkan benda tiruan sebagai memperkaya pengetahuan terhadap Struktur Anatomi Tulang Manusia. Media benda tiruan atau model merupakan tiruan dari benda yang berbentuk tiga dimensi yang dibuat sedemikian rupa sehingga mirip dalam bentuk dan tidak sama dengan hal hal lain. Media tiruan harus memenuhi 4 karakteristik (Sihkabuden, 2017) pertama dengan adanya perubahan ukuran, model lebih mudah dipelajari. Misalnya model yang diperkecil dan model yang diperbesar. Kedua bagian-bagian yang tidak penting dihilangkan, agar pebelajar dapat dengan mudah mengamati bagian yang penting saja. Misalnya melalui model yang disederhanakan. Ketiga dapat mempertunjukan struktur bagian dalam suatu benda, melalui model irisan supaya orang dapat melihat dalam suatu benda yang tidak mungkin melihat dalam keadan aslinya. Keempat kekongkritan yang tak langsung. Melalui model siswa medapatkan pengalaman yang kongkrit walaupun tidak melalui benda yang sebenarnya. Maka dari itu dibutuhkan pembuatan model tiruan 3 Dimensi Hologram yang memenuhi 4 karakteristik tersebut dengan adanya irisan, bentuk diperkecil, semua bagiannya bisa dipelajari dan memiliki tekstur agar benda terlihat seperti nyata. Pengembangan manipulatif model objek 3 dimensi (3D) perlu diterapkan untuk sub materi struktur anatomi tulang manusia. Model 3D yang dikembangkan struktur anatomi tulang manusia, hal ini dilakukan untuk mengatasi kendala belajar di dalam kelas sebelumnya, supaya siswa bisa mengidentifikasi struktur anatomi tulang manusia

Holografi merupakan teknik yang dapat memungkinkan cahaya pada benda dapat tersebar kemudian dapat direkonstruksi ulang. Teknik ini menghasilkan bayangan 3D didasarkan pada peristiwa interfensi dan direkam dengan tingkat medium 2D, pada medium inilah yang dikatakan hologram. Istilah hologram dari yunani kuno "holos" berarti utuh dan "gram" artinya informasi. Hologram disebut juga gambar tiga dimensi yang isi informasinya tentang ukuran, kecerahan, bentuk, dan kekontrasan objek yang terekam (Arifah dkk., 2007). Piramida sendiri menunjukan bahwa gambar hologram akan ditampilkan seolah-olah terdapat didalam piramida. Piramida ini terbuat dari bahan akrilik atau kaca yang berbentuk seperti piramida yang berguna sebagai tempat untukmerefleksikan gambar yang dimunculkan oleh layar monitor atau televisi. Ketebalan kaca mika, layar monitor dan ukuran objek mempengaruhi hasil dari terbentuknya objek animasi 3 dimensi dalam bentuk hologram (Tawaqqal dkk., 2017)

Dari permasalahan yang telah disebutkan maka dikembangkanlah video 3D hologram sebagai media pembelajaran materi IPA sistem gerak manusia. Penyajian video 3D hologram tersebut terdapat gambar struktur anatomi tulang manusia yang mempunyai warna, tekstur dan bentuk yang sama dengan aslinya. Tujuan dikembangkannya produk video 3D hologram supaya siswa memiliki rasa motivasi, kemenarikan, kemudahan dengan media 3D tersebut.

\section{METODE}

Model pengembangan penelitian yang digunakan yaitu model penelitian dan pengembangan (Research \& development) yang dikemukakan oleh Lee \& Owen, pemilhan model ini relevan dan selaras dengan pengembangan multimedia (Alamsyah dkk., 2019). Dengan alasan pemilihan model Lee \& Owen pada komponen yang terdapat dalam media objek 3D video digital, selain hal tersebut model Lee \& Owen disetiap langkah pengembangan memiliki langkah yang tersusun jelas dan lengkap. (Lee \& Owen) menyatakan terdapat lima tahap pengembangan sebagai berikut dengan tahapan sebagai berikut : analisis (analysis), desain (design), pengembangan (development) ,penerapan (implementasi) evaluasi (evaluation) seperti yang terdapat pada gambar 1. 


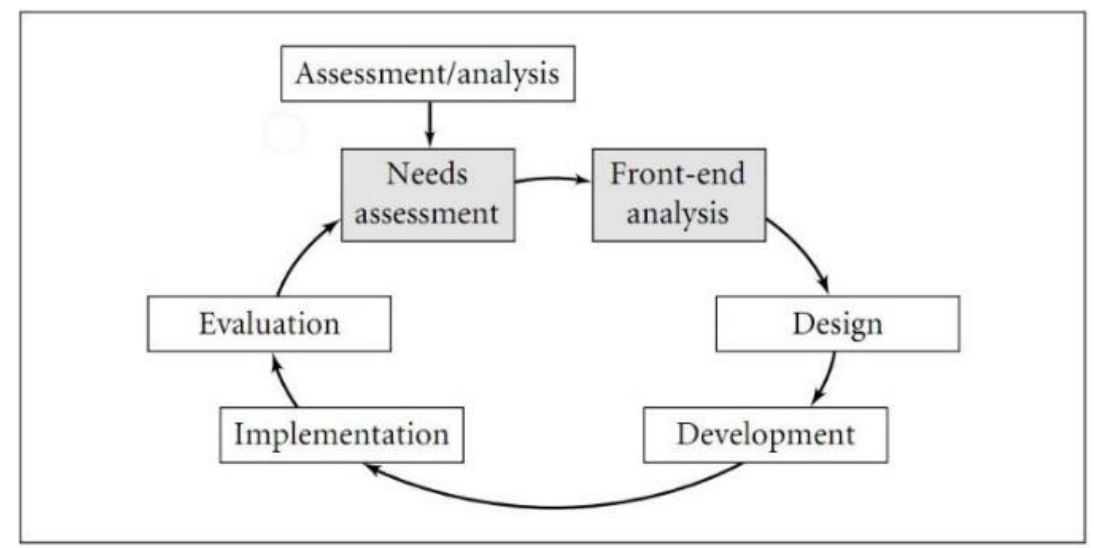

Gambar 1. Model penelitian dan pengembangan William W. Lee \& Diana L. Owens.

Uji coba produk dilakukan kepada ahli media, ahli materi dan 5 orang siswa secara langsung di dalam kelas. Instrumen yang digunakan adalah angket respon atau tanggapan untuk ahli media, ahli materi dan siswa dengan kisi-kisi yang telah disiapkan. Angket untuk ahli media terdapat 11 butir yang terdapat kisi-kisi aspek kemenarikan dan kemudahan, untuk angket ahli materi terdapat 9 butir yang terdapat kisi-kisi aspek kemenarikan dan kemudahan, untuk angket siswa terdapat 11 butir yang terdapat kisi-kisi aspek kemenarikan, kemudahan dan motivasi

\section{HASIL}

Pada tahap Need Assesment dilakukan observasi pengembangan saat melakukan wawancara kepada salah satu guru IPA kelas VIII di SMPN 4 Malang, Guru IPA kelas VIII Mengatakan bahwa pada saat dikelas buku yang dibagikan oleh guru kurang memberikan gambaran objek, dan alat peraga tulang manusia bentuknya besar dan hanya ada satu disekolah tersebut yang menyebabkan, siswa bila ingin mempelajari struktur anatomi tulang manusia tersebut harus bergantian, maka dari itu dibutuhkan media tiruan yang lebih kecil dan bisa dibagikan kepada seluruh siswa agar bisa dipelajari tanpa harus bergantian. Harapan dari pengembangan ini adalah objek 3D memanfaatkan piramida hologram membantu siswa mempelajari struktur anatomi tulang manusia

Pada tahap front-end-analysis dilakukan analisis untuk memperoleh informasi lebih detail, dengan mengidentifikasi latar belakang dan karakteristik pembelajaran, dengan menetapkan jenis teknologi yang akan dimanfaatkan untuk menyediakan solusi dalam permasalahan, produk digunakan sebagai kebutuhan belajar didalam kelas. Selanjutnya, menganalisis atau menentukan mana yang mengharuskan disampaikan dan mana yang tidak harus disampaikan dalam media 3D digital sehingga bisa lebih efektif sesuai dengan kebutuhan yang sebenarnya. Langkah selanjutnya mengkategorikan bahan yang akan digunakan untuk mengembangkan media 3D termasuk perangkat keras, perangkat lunak serta materi dari beberapa referensi di internet. Media objek 3D dengan hasil eksport berbentuk file video, dengan bertujuan digunakan di perangkat handphone sehingga mudah dipelajari kapanpun dan dimanapun.

Pada tahap ini adalah tahap desain atau perencanaan media. Tahap ini mencakup keseluruhan pengembangan objek 3D memanfaatkan piramida hologram berbasis smartphone. Pengembangan menyusun jadwal (schedule), menentukan spesifikasi media (media spesification), struktur konten (content structure), kemudian kontrol konfigurasi (configuration control). Dalam proses perancangan meliputi pembuatan flowchart, storyboard, dan rancangan antarmuka pemakai. Berikut tampilan desain piramida hologram yang terdapat pada gambar 2 


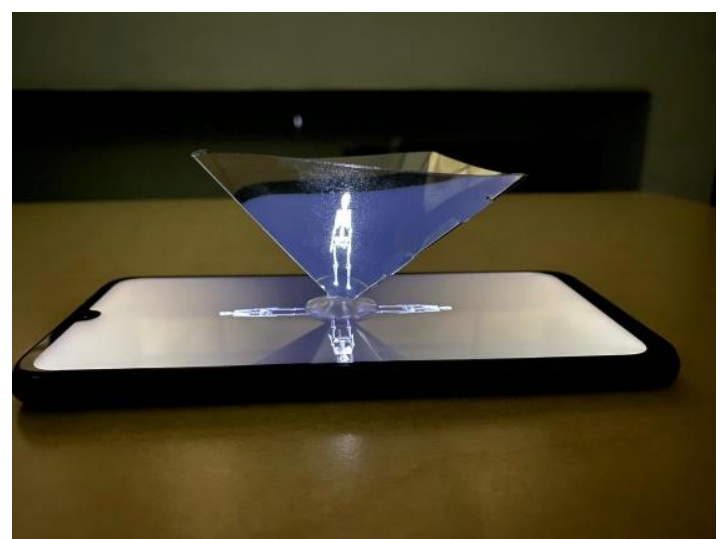

Gambar 2. Tampilan Desain Piramida Hologram

Tahap selanjutnya yaitu development \& implementation, software yang digunakan untuk membuat video 3D digital adalah blender, setelah membuat video 3 dimensi digital ini digunakannya software adobe primere untuk memberikan teks dan audio. Audio sendiri sebelumnya sudah diedit dengan menggunakan Adobe Audition agar suara/narasi tersebut dapat terdengar dengan jelas. Setelah melakukan serangkaian proses tersebut. objek yang telah ditambahkan audio dan teks di atur menjadi empat sisi, kemudian dirender dan dieksport sehngga menjadi bahan ajar berupa video. Setelah tahap pembuatan video 3 dimensi digital tahap selanjutnya yaitu implementation, tahap ini diuji kelayakan kepada ahli media, ahli materi dan siswa.

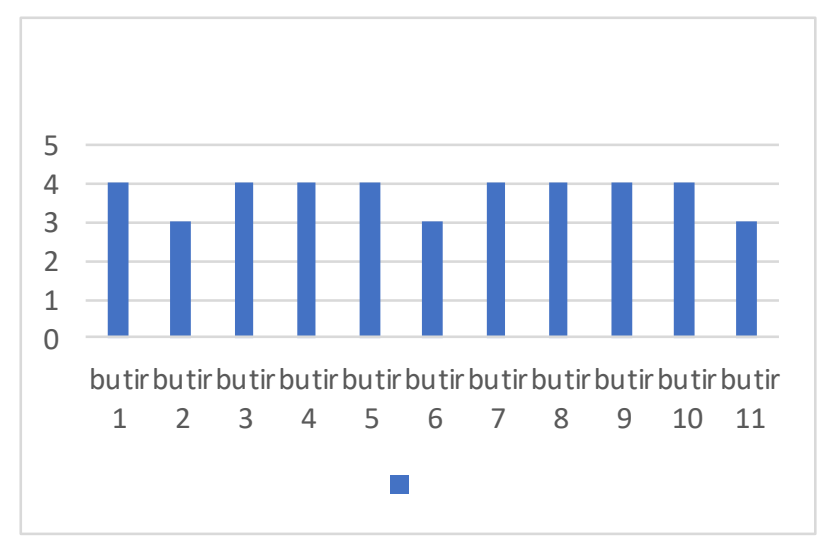

\section{Grafik 1. Hasil Review Ahli Media}

Data validasi produk pengembangan media objek yang diperoleh dalam pengembangan ini tedapat dari instrumen pengumpulan data yang dipakai berupa angket. Dalam penelitian pengembangan objek menggunakan jenis angket tertutup. Sehingga responden atau siswa mengisis pertanyaan dan pilihan jawaban secara terbatas. Dalam implementasi produk media 3D diperoleh hasil dilihat grafik 1 dan grafik 2.

Hasil uji kelayakan yang terdapat pada grafik 1 kepada ahli media persentase dengan tanggapan positif $100 \%$, persentase tanggapan SS $73 \%$, persetanse tanggapan S $27 \%$ mean 3,7, median 3, dan modus 3 sehingga dapat disimpulkan media 3D piramida hologram layak digunakan dalam proses pembelajaran. 


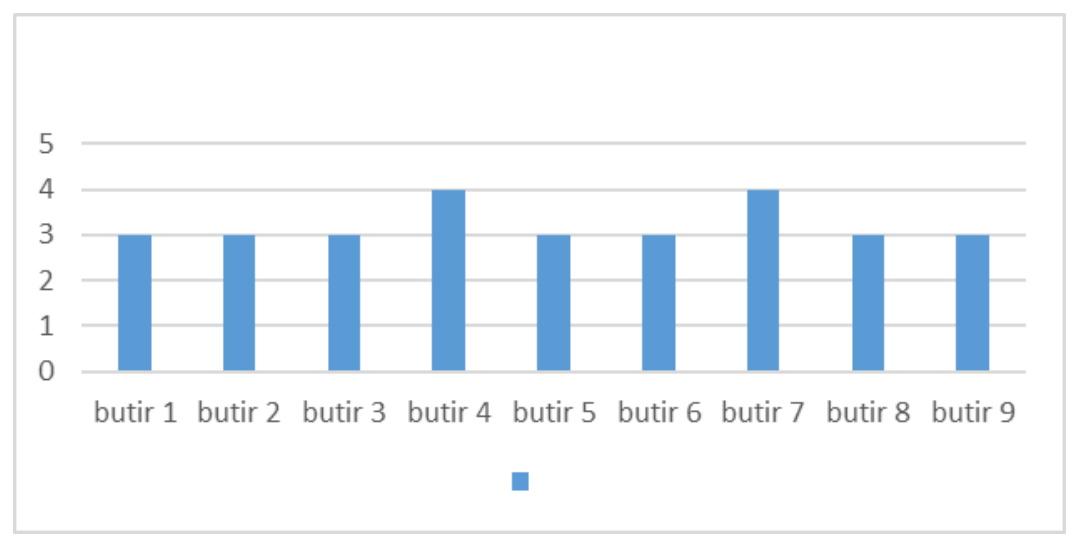

Grafik 2. Hasil Review Ahli Materi

Uji coba produk melibatkan 5 siswa kelas VIII SMPN 4 Malang. Berdasarkan analisis respon siswa terdapat 11 butir pernyataan, 10 butir pernyataan mendapatkan persentase $100 \%$ jawaban positif dan 1 butir pernyataan mendapat 80\% jawaban positif. Keseluruhan jawaban positif dari 11 butir pernyataan yaitu 98,1\%,presentase jawaban SS $54 \%$, presentase jawaban S $44 \%$ dan jawaban TS $1 \%$, dengan mean 3,52, median 3, dan modus 4 sehingga dapat disimpulkan bahwa objek video 3D disimpulkan media 3D piramida hologram layak digunakan dalam proses pembelajaran. proses pembelajaran IPA kelas 8 .

\section{PEMBAHASAN}

Pada pengembangan media objek 3D memanfaatkan piramida hologram berbasis smartphone materi sistem gerak manusia telah melalui uji kelayakan pada ahli media, ahli materi dan uji coba sebanyak 5 siswa dengan penerapan secara offline, dengan kondisi rungan yang tidak cukup terang, 5 orang siswa dibentuk melingkar sehingga media objek 3 dimensi digital terlihat jelas, dikarenakan objek 3 dimensi digital ini membutuhkan pencahayaan yang tidak terlalu terang agar gambar 3 dimensi tersebut terlihat jelas.

Hasil uji kelayakan objek 3D memanfaatkan piramida hologram berbasis smartphone materi sistem gerak manusia kepada ahli media mendapatkan respon positif, hasil uji kelayakan kepada ahli media mendapat respon tanggapan positif $100 \%$, presentase tanggapan SS sebanyak $73 \%$, presentase tanggapan S $27 \%$ mean 3,7, median 3, dan modus 3 sehingga dapat disimpulkan media 3D piramida hologram layak digunakan dalam proses pembelajaran, ahli media memberikan komentar secara umum cukup bagus, menarik, inovatif, untuk efektifitas mengacu pada tujuan pembelajaran, perlu keselarasan dengan pembelajaran yang dikembangkan guru/pengajar, serta sinergis dengan sumber belajar yang lain, lengkapi dengan petunjuk pemanfaatan, serta identitas serta profil produk/media.

Tahap berikutnya uji kelayakan kepada ahli materi, medapatkan respon tanggapan positif tanggapan positif 89,\%, persentase tanggapan SS $11 \%$, persetanse tanggapan S $78 \%$ mean 3, median 3, dan modus 3 sehingga dapat disimpulkan media 3D piramida hologram layak digunakan dalam proses pembelajaran, ahli materi memberikan komentar tersebut ialah video struktur anatomi tulang manusia lebih divariasikan dengan gerakan-gerakan agar lebih menarik.

Sedangkan uji kelayakan kepada siswa keseluruhan mendapatkan respon tanggapan positif $98,1 \%$, mean 38, median 4, modus 4 sehingga dapat disimpulkan media 3D piramida hologram layak digunakan dalam proses pembelajaran, terdepat 1 butir siswa menjawab TS butir tersebut berisi "Ukuran gambar yang ditampilkan pada objek media 3 dimensi digital sudah tepat" 1 siswa menjawab TS dikarenakan ukuran gambar pada objek 3 dimensi digital dirasa terlalu kecil. Tetapi secara keseluruhan tanggapan dari 5 orang siswa SMPN 4 Malang mengenai objek 3 dimensi 
memanfaatkan piramida hologram materi sistem gerak manusia ini media sangat menarik, memberikan kemudahan kepada peserta didik agar mau untuk mempelajari materi dan memotivasi siswa untuk mau mempelajari materi sistem gerak manusia

Dalam proses pembelajaran mata pelajaran IPA Biologi siswa hanya dijelaskan oleh guru secara verbal kurang memberikan gambaran materi, hal tersebut membuat siswa hanya bisa menerka-nerka dengan materi yang disampaikan oleh guru, (Fitriani dkk., 2020) Belajar menggunakan teori saja tidak akan membuat peserta didik pandaimenangkapapa yang harus mereka kuasai secara detail dalam pembelajaran IPA di SMP. Terlebih pada siswa yang memiliki minat baca rendah, sehingga sulit untuk membuat siswa mengerti terhadap apa yang harus mereka pelajari. Penggunaan media 3D hologram sebagai alat pengajaran yang tepat untuk meningkatkan minat siswa ketika belajar dan juga meningkatkan pemahaman siswa saat dikelas, selain itu bisa menambah wawasan bagi guru untuk menjadikan teknologi 3D hologram sebagai pengganti metode pembelajaran tradisional (Barkhaya \& Halim, 2016). Objek yang ditampilkan bisa interaktif dengan pengguna jika mempunyai alat pendeteksi sensor gerak tubuh seperti penelitian yang telah dilaksanakan (Ryu dkk., 2016) pada saat uji coba melakukan pameran digital objek 3 dimensi. Hasilnya piramida hologram adalah teknologi yang mampu menarik pengguna dikarenakan objek digital yang ditampilkan dapat berinteraksi langsung dengan pengguna, sehingga pengguna merasakan objek 3 dimensi yang realistis di dalam cermin piramida,

Kelebihan pengembangan objek 3D memanfaatkan piramida hologram berbasis smartphone dari pengembangan sebelumnya yang berhubungan dengan video objek 3 dimensi digital memanfaatkan piramida hologram yang diteliti (Soepriyanto dkk., 2019) tentang pengembangan objek 3D digital piramida hologram untuk pembelajaran kelas, selanjutnya penelitian yang dilakukan (Kurniawan dkk., 2019) tentang pengembangan vacum circuit breaker untuk memfasilitasi belajar taruna didalam kelas. Penelitian selanjutnya (Roslan \& Ahmad, 2017) penelitian yang berjudul 3D Spatial Visualization Skills Training Application for Schools, penelitian tersebut membandingkan 3 tes Paper Folding Task (PFT), Mental RotationTask (MRT), and Virtual Building Component (VBC), Penelitian selanjutnya (Arifudin dkk., 2019) tentang pengembangan objek 3D memanfaatkan piramida hologram materi sel hewan dan tumbuhan (Kalarat, 2017) bahwa penerapan 3D hologram tepat digunakan dimasa depan sebagai teknologi penyalur pesan. Penelitian berikutnya (Sari dkk., 2020) tentang digitalisasi media objek 3D kabel fiber optik berbantuan piramida hologram, pengembangan objek 3D hologram sebelumnya mengasilkan objek 3D digital memanfaatkan piramida yang ukurannya cukup besar sehingga tidak bisa dipelajari dimana saja oleh pengguna. Keunggulan dalam pengembangan ini menghasilkan objek media 3D memanfaatkan piramida hologram ini produk yang dihasilkan video 3 dimensi digital yang diperuntukan untuk smartphone dan menggunakan alat proyeksi piramida hologram yang berbentuk kecil, sehinggal menghasilkan objek 3D yang berukuran kecil, dengan adanya perubahan.

Tidak hanya di dunia pendidikan saja tetapi penggunaan hologram juga diterapkan untuk kampanye sosial dan dunia kedokteran, penerapan hologram untuk kampanye sosial yang telah diterapkan (Wijaya dkk., 2019) dalam perancangan kampanye sosial ini, dibuat video hologram 3D tentang penyu yang bertujuan untuk dapat memberikan informasi tentang penyu secara unik dan inovatif dengan memanfaatkan teknologi piramida hologram, dalam dunia medis penelitian yang dilakukan oleh (Than dkk., 2018) menghasilkan penelitian bahwa objek yang ditampilkan pada piramida hologram membuat pengguna dapat menjeda video kapan saja untuk menunjukkan struktur gambar yang diinginkan, pemanfaatan hologram untuk dunia medis juga diterapkan oleh (Thap dkk., 2016) salah satu pemanfaatan hologram dapat diterapkan untuk menunjukan objek 3 
dimensi holografik detak jantung manusia, sehingga objek yang dimunculkan akan terlihat efektif dengan menyenangkan bagi pengguna, sensitif, menarik, dan mirip dengan objek aslinya.

Penggunaan teknologi hologram sangat cocok diterapkan untuk proses pembelajaran dimasa depan dikarenakan menampilkan objek 3 dimensi secara detail dan bentuknya hampir sama dengan objek nyata. Terdapat enam keuntungan yang telah dikemukakan oleh (Khan dkk., 2020) pertama siswa mendapat keuntungan untuk melihat komponen pada objek 3D yang ditampilkan pada piramida hologram, kedua tampilan hologram menghasilkan tampilan 360 yang dapat dilihat dari sudut manapun, ketiga hologram menambah kedalaman dan rasa realitas untuk meningkatkan hasil belajar keempat model dalam skala aktual bermanfaat bagi proses pembelajaran kelima, teknik holografi memiliki kemampuan untuk memproduksi ulang kenyataan dan merupakan cara yang luar biasa untuk memotivasi siswa, keenam teknologi hologram menawarkan model tambahan untuk pembelajaran. Akan tetapi hologram memiliki beberapa kekurangan seperti yang diutrakan oleh (Kurniawan, 2016) komunikasi lebih banyak dari satu arah dikarenakan pengguna tidak bisa berinterksi langsung dan bertanya dengan objek dalam hologram, membutuhkan alat-alat pendukung untuk menerapkan teknologi hologram, penerapan teknologi hologram membutuhkan gabungan multimedia yang lengkap dan cenderung sangat rumit

\section{SIMPULAN}

Pengembangan Objek 3D Memanfaatkan Piramida Hologram Berbasis Smartphone Sistem Gerak Manusia untuk SMP untuk mengatasi permasalahan antara siswa dan guru, Siswa dapat mengamati objek 3 dimensi digital memanfaatkan piramida hologram dari berbagai sisi dan penggunaan objek 3 dimensi digital tersebut praktis bisa digunakan dimana saja dikarenakan bisa ditampilkan melalui smartphone. Tetapi terdapat kelemahan yang dapat diperbaiki pada objek 3 dimensi memanfaatkan piramida hologram sistem gerak manusia ini seperti gambar yang ditampilkan terlalu kecil. Hasil validasi ahli media, ahli materi dan 5 siswa SMP kelas VIII mendapatkan tanggapan positif dan layak digunakan sebagai media pembelajaran IPA Biologi, Berdasarkan hasil penelitian yang sudah dilakukan, menunjukan bahwa objek 3D memanfaatkan piramida hologram berbasis smartphone sistem gerak manusia memberikan kemudahan dalam pembelajaran, memotivasi siswa untuk belajar, menampilkan media yang menarik untuk siswa.

\section{DAFTAR RUJUKAN}

Alamsyah, R., Toenlioe, A. J., \& Husna, A. (2019). Pengembangan video pembelajaran kepenyiaran materi produksi program televisi untuk mahasiswa Teknologi Pendidikan Universitas Negeri Malang. Jurnal Kajian Teknologi Pendidikan, 1(3), 229-236.

Andriyani, A., Dewi, H. I., \& Zulfitria, Z. (2020). Penggunaan Multimedia dan Animasi Interaktif Terhadap Keterampilan Membaca Permulaan SISWA. Instruksional, 1(2).

Arifah, A., Firdausi, K. S., \& Azam, M. (2007). Pembuatan Hologram Refleksi. BERKALA FISIKA, 10(3), 127-135.

Arifudin, A., Kuswandi, D., \& Soepriyanto, Y. (2019). Pengembangan Media Obyek 3 Dimensi Digital Sel Hewan dan Tumbuhan Memanfaatkan Piramida Hologram Untuk MTS. Jurnal Kajian Teknologi Pendidikan, 2(1), 9-15.

Barkhaya, N. M. M., \& Abd Halim, N. D. (2016). A review of application of 3D hologram in education: A meta-analysis. 2016 IEEE 8th International Conference on Engineering Education (ICEED), 257-260.

Fitriani, A. A., Ulfa, S., \& Adi, E. P. (2020). Pengembangan Video Pembelajaran Animasi Sistem Pernapasan Manusia Sebagai Upaya Mendukung Kebijakan Belajar Di Rumah. Jurnal Kajian Teknologi Pendidikan, 3(3), 303-316.

Hermawan, H., Riyana, C., \& Zaman, B. (2007). Media Pembelajaran SD. Bandung: Upi Pres. 
Kadir, A. (2013). Konsep pembelajaran kontekstual di sekolah. Dinamika Ilmu: Jurnal Pendidikan, 13(1).

Kalarat, K. (2017). The use of 3D holographic piramida for the visualization of Sino-Portuguese architecture. Journal of Informatio N, 2(5), 18-24.

Khan, A., Mavers, S., \& Osborne, M. (2020). Learning by Means of Holograms. Society for Information Technology \& Teacher Education International Conference, 1134-1139.

Kurniawan, C. (2016). Pengembangan Model Pembelajaran 3D Display System Berbasis Holografi. Sinteks: Jurnal Teknik, 5(2).

Kurniawan, D. A., Astalini, A., Darmaji, D., \& Melsayanti, R. (2019). Students' Attitude towards Natural Sciences. International Journal of Evaluation and Research in Education, 8(3), 455-460.

Kurniawan, D., Susilaningsih, S., \& Soepriyanto, Y. (2019). Pengembangan Media Obyek 3D Vacuum Circuit Breaker Memanfaatkan Piramida Hologram. Jurnal Kajian Teknologi Pendidikan, 2(1), 16-22.

Resnick, M. (2002). Rethinking learning in the digital age. The global information technology report: Readiness for the networked world ....

Roslan, R. K., \& Ahmad, A. (2017). 3D Spatial Visualisation Skills Training Application for School Students Using Hologram Piramida. JOIV: International Journal on Informatics Visualization, 1(4), 170-174.

Ryu, J., Kim, M., Min, Y., Jung, M., Lee, J., Lee, S., Cho, E., \& Joo, W. (2016). Exhibition Strategy of Digital 3D Data of Object in Archives using Digitally Mediated Technologies for High User Experience.

Saraswati, D. (2017). Peningkatan Hasil Belajar IPA Melalui Metode Problem Based Learning Berbantuan Video Pembelajaran Serta Implikasinya Dalam Pelayanan Bimbingan dan Konseling di Sekolah Dasar. Jurnal Konseling Gusjigang, 3(2).

Sari, M. R., Soepriyanto, Y., \& Wedi, A. (2020). Digitalisasi Media Objek 3 Dimensi Kabel Fiber Optic Berbantuan Piramida Hologram Untuk Sekolah Menengah Kejuruan. Jurnal Kajian Teknologi Pendidikan, 3(4), 366-376.

Sihkabuden. (2017). Media Pembelajaran. Tidak diterbitkan.

Soepriyanto, Y., Sihkabuden, S., \& Surahman, E. (2019). Pengembangan Obyek 3D Digital Pada Meja Piramida Hologram Untuk Pembelajaran Kelas. Jurnal Kajian Teknologi Pendidikan, 1(4), 333-339.

Tawaqqal, I., Ningrum, I. P., \& Yamin, M. (2017). Hologram Holographic Piramida 3 Dimensi. semanTIK, 3(1).

Than, M. H., Pham, M. M., \& Pham, H. T.-T. (2018). Piramida Hologram in Projecting Medical Images. International Conference on the Development of Biomedical Engineering in Vietnam, 421-426.

Thap, T., Chung, H., \& Lee, J. (2016). Heart activity monitoring using 3D hologram based on smartphone. 2016 38th Annual International Conference of the IEEE Engineering in Medicine and Biology Society (EMBC), 5339-5342.

Wijaya, Y. K., Nasrulloh, M., \& Bangsawan, A. (2019). Perancangan Kampanye Sosial Tentang Penyu di Indonesia Melalui Teknik Hologram 3D Untuk Dewasa Awal Usia 18-40 Tahun. Artika, 4(1), 53-60. 